\title{
The role of plasma exchange in acute liver failure of autoimmune etiology
}

\author{
Selim Gökçe ${ }^{1 \oplus}$, Banu Bal Çermik ${ }^{2 \oplus}$, Nurettin Onur Kutlü ${ }^{3 \oplus}$, İhan Ocak ${ }^{4 \oplus}$ \\ ${ }^{1}$ Department of Pediatric Gastroenterology, Hepatology and Nutrition, İstanbul Yeni Yüzyıl University, Gaziosmanpaşa Hospital, \\ Istanbul; Departments of ${ }^{2}$ Pediatric Gastroenterology, Hepatology and Nutrition and ${ }^{3}$ Pediatric Intensive Care, Bezmialem Vakıf \\ University, İstanbul, ${ }^{4}$ Intensive Care Unit, İstanbul Memorial Hospital, İstanbul, Turkey.
}

\begin{abstract}
Background. Autoimmune hepatitis $(\mathrm{AIH})$ is characterized by increased immunoglobulin G (IgG) levels, the presence of autoantibodies, and various degrees of lymphocyte predominant inflammation and fibrosis histologically. Immunosuppressive therapy induces remission in approximately $80 \%$ of those affected. However, liver transplantation is indicated in patients with acute liver failure with encephalopathy at presentation. Liver supporting systems, including plasma exchange (PE) allow bridging patients to transplantation or spontaneous recovery in the setting of liver failure. The role of these systems has not been assessed in children with liver failure of autoimmune etiology.
\end{abstract}

Case. Herein, we report three cases of AIH with fulminant presentation, with marked symptom resolution with $\mathrm{PE}$ as an adjunct therapeutic option to immunosuppressive treatment.

Conclusion. In the setting of AIH, PE may have a special therapeutic role by removing autoantibodies and cytokines, therefore preventing further liver damage and decompensation, and allowing time for recovery

Key words: children, plasma exchange, treatment, autoimmune hepatitis.

\begin{abstract}
Autoimmune hepatitis (AIH) is an immunologically mediated inflammatory liver disorder of unknown etiology. It is characterized by increased immunoglobulin G (IgG) levels, the presence of autoantibodies, and interface hepatitis described as dense inflammatory infiltrate composed of lymphocytes and plasma cells, which crosses the limiting plate and invades the surrounding parenchyma and fibrosis histologically. AIH is particularly aggressive in children and progresses rapidly unless immunosuppressive treatment is started promptly. The mode of AIH presentation includes acute hepatitis, chronic
\end{abstract}

Selim Gökçe

drgokce0007@yahoo.com

Received 30th March 2020, revised 2nd May 2020,

17th May 2020, accepted 17th May 2020.

Role of plasmapheresis in acute liver failure of autoimmune etiology. H-P-041. European Society for Pediatric Gastroenterology, Hepatology and Nutrition 49th Annual Meeting, 25-28 May 2016, Athens, Greece. liver disease and its complications, incidental finding of raised transaminases, insidious onset characterized by nonspecific symptoms and fulminant AIH. ${ }^{1}$ Pediatric acute liver failure is described as biochemical evidence of acute liver injury, and hepatic-based coagulopathy defined as a prothrombin time $(\mathrm{PT}) \geq 15$ seconds or international normalized ratio (INR) $\geq 1.5$ not corrected by Vitamin $\mathrm{K}$ in the presence of clinical encephalopathy or a PT $\geq 20$ seconds or INR $\geq 2.0$ regardless of the presence or absence of encephalopathy. ${ }^{2}$ It is seen in approximately $3 \%$ of patients with type- $1 \mathrm{AIH}$ and $25 \%$ of patients with type-2 AIH. With appropriate treatment, $80 \%$ of patients achieve remission and longterm survival. However, liver transplantation is indicated in patients who present with fulminant hepatic failure (with encephalopathy) unresponsive to steroid treatment and those who develop end-stage liver disease. ${ }^{1,3}$ Liver supporting systems, including plasma exchange (PE) allow bridging patients to transplantation 
or spontaneous recovery in the setting of liver failure. ${ }^{4}$ The role of these systems has not been assessed in children with liver failure of autoimmune etiology. Herein, we report three cases of AIH with fulminant presentation, with marked symptom resolution with PE adjunct to immunosuppressive treatment.

\section{Case 1}

A 6-year-old girl was admitted to the hospital with jaundice for the previous 6 days. There was no history of a particular illness or drug use. Family history was unremarkable. She was icteric, with slight hepatomegaly. Laboratory findings were aspartate aminotransferase (AST) $1314 \mathrm{IU} / \mathrm{L}$, alanine aminotransferase (ALT) $837 \mathrm{IU} / \mathrm{L}$, total bilirubin (TB) $28.17 \mathrm{mg} /$ $\mathrm{dl}$, direct bilirubin (DB) $24.31 \mathrm{mg} / \mathrm{dl}$, INR 3.65 (unresponsive to vitamin $\mathrm{K}$ ) and ammonia 57 $\mathrm{mg} / \mathrm{dl}$. Further investigations revealed $\mathrm{IgG}$ $4245.7 \mathrm{mg} / \mathrm{dl}$ (633-1280), ceruloplasmin 49.4 $\mathrm{mg} / \mathrm{dl}$, and a positive antinuclear antibody (ANA), titer $\geq 1 / 100$. Viral serologies of Hepatitis A, B, C, E, Epstein-Barr Virus (EBV), and cytomegalovirus (CMV) were all negative. She rapidly progressed to grade 3 encephalopathy under prednisolone $(2 \mathrm{mg} / \mathrm{kg} /$ day $)$ and $\mathrm{PE}$ was started. After three daily sessions of PE, the patient was non-encephalopathic. After the second week of prednisolone treatment, azathioprine was added. Liver biopsy performed one month after hospitalization demonstrated minimal portal inflammation, giant cell formation, cholestasis, and grade 2 to 3 portal fibrosis. At the end of one month, the patient was tolerating the azathiopurine and the prednisolone dosage was tapered. She is in complete remission longer than 2 years with no recurrence (Table I).

\section{Case 2}

A 10-year-old boy presented with abdominal pain and jaundice. Laboratory tests revealed elevated transaminase levels. INR was 1.96 (unresponsive to vitamin K). Viral serologies were negative for Hepatitis A, B, C, EBV, and CMV. The anti-smooth muscle antibody (ASMA) test was positive (titer $>1 / 160$ ), and the serum IgG value was $4745 \mathrm{mg} / \mathrm{dl}$ (608-1572). A liver biopsy was not performed owing to coagulopathy. Prednisolone was started at a dosage of 2 $\mathrm{mg} / \mathrm{kg} /$ day. On the 4 th day of prednisolone administration, the patient developed grade 2 encephalopathy and the INR was 2.1. After three PE sessions, the patient showed improvement. Liver biopsy performed on the 20th day of prednisolone treatment demonstrated resolution of acute hepatitis, pericentral and periportal bridging fibrosis and necrosis along with portal mononuclear dominant mixed inflammatory cell infiltration. These biopsy findings under immunosuppressive treatment together with clinical and laboratory findings were supporting the diagnosis of $\mathrm{AIH}$. He

Table I. The course of ALT, bilirubin and INR values.

\begin{tabular}{lllllllll}
\hline & Days & Initial $^{*}$ & 3 & 7 & 15 & 30 & 60 & 90 \\
\hline \multirow{2}{*}{ Case 1} & ALT (IU/L) & 711 & 316 & 225 & 513 & 197 & 99 & 87 \\
& T. bilirubin (mg/dl) & 28.11 & 9.85 & 11.30 & 12.30 & 3.90 & 1.30 & 0.92 \\
& INR & 3.67 & 2.23 & 2.34 & 1.71 & 1.32 & 1,27 & 1.21 \\
& ALT (IU/L) & 501 & 60 & 96 & 63 & 92 & 34 & 31 \\
& T. bilirubin (mg/dl) & 4.00 & 1.42 & 1.34 & 1.00 & 0.98 & 0.910 & 1.15 \\
& INR & 2.1 & 1.48 & 1.64 & 1.4 & 1.18 & 1.07 & 1.33 \\
& ALT (IU/L) & 405 & 120 & 318 & 351 & 253 & 47 & 56 \\
& T. bilirubin (mg/dl) & 17.60 & 13.40 & 10.9 & 7.9 & 4.3 & 0.8 & 0.3 \\
& INR & 3.51 & 2.02 & 2.49 & 1.91 & 1.24 & 1.26 & 1.13 \\
\hline
\end{tabular}

*Day 0; first day of plasmapheresis

ALT: alanine aminotransferase, INR: international normalized ratio. 
was discharged on prednisolone treatment and all laboratory findings were normalized by the second month of treatment. He is now in complete remission without any recurrence longer than 3 years under low dose methylprednisolon and azathiopurine (Table I).

\section{Case 3}

A 2-year-old girl was referred to the hospital with grade 2 encephalopathy. She had a threemonth history of jaundice. Physical examination showed slight hepatomegaly and splenomegaly. Laboratory findings at presentation were as follows: AST 427 IU/L, ALT 412 IU/L, TB 15.43 $\mathrm{mg} / \mathrm{dl}$, DB $12.23 \mathrm{mg} / \mathrm{dl}$, INR 3.51, and ammonia $187 \mathrm{mg} / \mathrm{dl}$. Viral, toxic, and metabolic causes were excluded. IG value was $1888 \mathrm{mg} / \mathrm{dl}$ (453916). She tested positive for ANA (titer 1/160) and ASMA (titer 1/80). Prednisolone and PE treatments were commenced immediately. After three daily sessions of PE, she was nonencephalopathic. Despite the correction of the INR values, transaminases did not decrease and cyclosporine therapy (PO) was started. Liver biopsy demonstrated resolution of acute hepatitis along with slight portal mononuclear cell infiltration and pericentral and periportal fibrosis. Transaminase levels were declining and the INR value was completely normalized at the end of the first month following admission, while she was on prednisolone and cyclosporine. By the $3^{\text {rd }}$ month of presentation, she was under the cyclosporine maintenance treatment. Unfortunately, she died of severe pneumonia and sepsis 6 months later while she was in complete remission (Table I).

\section{Discussion}

The mainstay of treatment in AIH is immunosuppressive therapy and should be instituted promptly to avoid progression to cirrhosis. The conventional treatment consists of prednisolone $2 \mathrm{mg} / \mathrm{kg} /$ day, which is gradually tapered in due course within 4-8 weeks, in parallel to decline in transaminase levels, to a maintenance dose of 2.5 to $5 \mathrm{mg} /$ day. $^{5,6}$ In the pediatric age, remission is defined as complete clinical recovery with transaminase levels within the normal range and is achieved in $60 \%$ to $90 \%$ of patients, except fulminant presentation with encephalopaty. ${ }^{3}$ The management of AIH with fulminant presentation is controversial. Steroid treatment in fulminant patients is considered to be of little benefit and increase septic complication in adults. ${ }^{7}$ On the other hand, recovery was reported in 4 out of 9 children referred to the transplant center while the remaining 5 required liver transplant despite steroids. ${ }^{8}$ Smolka at al. reported complete response in all 6 children presenting with $\mathrm{AIH}$ with encephalopathy. ${ }^{9}$ In a report from India, 2 out of 4 children with fulminant $\mathrm{AIH}$ responded to steroid treatment, the other 2 died due to progressive encephalopathy and infectious complications. ${ }^{10}$ Karakoyun et al. ${ }^{11}$ reported AIH with encephalopathy in $2(4.3 \%)$ out of 44 patients who did not respond to steroid treatment and underwent living-related liver transplantation.

In the setting of acute liver failure, decompensation of liver function results in decreased biotransformation and excretion of toxic substances as well as synthetic functions. Most liver support systems are based on detoxification of water-soluble (ammonia, lactate, urea, GABA, amino acids, and cytokines) or albumin-bound (bile acids, bilirubin, free fatty acids, aromatic amino acids, indoles, phenols, mercaptans, and endogenous benzodiazepines) toxins. PE removes toxic substances and replaces essential substances by separating the patient's plasma from formed elements and replacing it with the same amount of fresh frozen plasma. ${ }^{12}$ High volume PE is considered as first line therapy in the setting of liver failure in adults, either as primary stand-alone treatment or in conjunction with other modes of treatment. ${ }^{13}$ Although PE is not recommended as standard of care for children with liver failure, it can be valuable as a temporizing measure because it rapidly removes large amounts of copper in patients with liver failure due to Wilson disease. Few studies of liver support systems 
have focused on pediatric patients and are mainly case series and retrospective studies. Most case series in children or adults with acute liver failure suggests that PE might improve coagulation profiles, vasopressor requirements, and encephalopathy grade scores. ${ }^{14-16}$ It can significantly decrease mortality in acute or acute-on-chronic liver failure by temporarily supporting liver functions until functional recovery or liver transplantation. ${ }^{17,18}$ On the other hand, Chien et al. ${ }^{19}$ reported in a case series of 23 pediatric patients that plasma exchange for more than six times probably offers little benefit with regard to patient survival in the absence of a timely liver transplant. In the present study, the first 2 cases developed encephalopathy under steroid treatment. The third case was already encephalopathic at admission. After three daily sessions of $\mathrm{PE}$, all cases were clinically non-encephalopathic, coagulation profiles and liver biochemistry improved and did not progress to encephalopathy in due course. Sogo et al. ${ }^{20}$ recently reported 4 children that presented with fulminant hepatic failure all survived by PE therapy initiated together with steroid and cyclosporine treatment. The data is limited regarding the role of PE in children with fulminant AIH. Moreover, no such data are available in adults with fulminant $\mathrm{AIH}$ refractory to medical treatment but improved by plasmapheresis. Dumortier et al. ${ }^{21}$ are reported a case of a liver transplanted adult female patient who presented a severe de novo $\mathrm{AIH}$, refractory to tacrolimus, mycophenolate mofetil and steroids, and who was treated with plasmapheresis. Only one case presenting with severe AIH-systemic lupus erythematosus overlap despite massive corticosteroid administration, and who improved with plasmapheresis therapy, has been reported..$^{22}$

Similar to the other liver supporting systems, PE allows bridging patients with acute liver failure to transplantation or spontaneous recovery. In the setting of $\mathrm{AIH}$, however, it may have a special therapeutic role as an adjunct to immunosuppressive treatment by removing autoantibodies and cytokines, therefore preventing further liver damage and decompensation, and allowing time for recovery. However, the data is limited and future well-designed studies are needed exploring the role of PE in fulminant $\mathrm{AIH}$.

\section{REFERENCES}

1. Vergani D, Mieli-Vergani G. Autoimmune hepatitis. In: Rodes J, Benhamou JP, Blei AT, Reichen J, Rizzetto $\mathrm{M}$, et al (eds). Textbook of Hepatology: From Basic Science to Clinical Practice (3rd ed) Chichester, UK: Blackwell Publishing, 2007: 1089-1101.

2. Squires $\mathrm{RH}, \mathrm{Ng} \mathrm{V}$, Romero R, et al. Evaluation of the pediatric patient for liver transplantation: 2014 practice guideline by the American Association for the Study of Liver Diseases, American Society of Transplantation and the North American Society for Pediatric Gastroenterology, Hepatology and Nutrition. Hepatology 2014; 60: 362-398.

3. Mieli-Vergani G, Vergani D, Baumann U, et al. Diagnosis and management of pediatric autoimmune liver disease: ESPGHAN Hepatology Committee Position Statement. J Pediatr Gastroenterol Nutr 2018; 66: 345-360.

4. Bacher A. Extracorporeal liver support with multipass albumin dialysis or plasmapheresis and filtering systems in acute liver failure. Liver Int 2011; 31(Suppl 3): 16-18.

5. Mieli-Vergani G, Vergani D. Paediatric autoimmune liver disease. Arch Dis Child 2013; 98: 1012-1017.

6. Floreani A, Liberal R, Vergani D, Mieli-Vergani G. Autoimmune hepatitis: contrasts and comparisons in children and adults - a comprehensive review. J Autoimmun 2013; 46: 7-16.

7. Ichai P, Duclos-Vallee JC, Guettier C, et al. Usefulness of corticosteroids for the treatment of severe and fulminant forms of autoimmune hepatitis. Liver Transpl 2007; 13: 996-1003.

8. Di Giorgio A, Bravi M, Bonanomi E, et al. Fulminant hepatic failure of autoimmune aetiology in children. J Pediatr Gastroenterol Nutr 2015; 60: 159-164.

9. Smolka V, Tkachyk O, Ehrmann J, Karaskova E, Zapalka M, Volejnikova J. Acute onset of autoimmune hepatitis in children and adolescents. Hepatobiliary Pancreat Dis Int 2020; 19: 17-21.

10. Ramachandran J, Sajith KG, Pal S, Rasak JV, Prakash JA, Ramakrishna B. Clinicopathological profile and management of severe autoimmune hepatitis. Trop Gastroenterol 2014; 35: 25-31. 
11. Karakoyun M, Ecevit CO, Kilicoglu E, Aydogdu S, Yagci RV, Ozgenc F. Autoimmune hepatitis and longterm disease course in children in Turkey, a singlecenter experience. Eur J Gastroenterol Hepatol 2016; 28: 927-930.

12. Stenbøg P, Busk T, Larsen FS. Efficacy of liver assisting in patients with hepatic encephalopathy with special focus on plasma exchange. Metab Brain Dis 2013; 28: 333-335.

13. Padmanabhan A, Connelly-Smith L, Aqui N, et al. Guidelines on the Use of Therapeutic Apheresis in Clinical Practice - Evidence-Based Approach from the Writing Committee of the American Society for Apheresis: The Eighth Special Issue. J Clin Apher 2019; 34: 171-354

14. Singer AL, Olthoff KM, Kim H, Rand E, Zamir G, Shaked A. Role of plasmapheresis in the management of acute hepatic failure in children. Ann Surg 2001; 234: 418-424.

15. Ide K, Muguruma T, Shinohara M, et al. Continuous veno-venous hemodiafiltration and plasma exchange in infantile acute liver failure. Pediatr Crit Care Med 2015; 16: e268-e274.

16. Larsen FS, Schmidt LE, Bernsmeier C, et al. Highvolume plasma exchange in patients with acute liver failure: an open randomised controlled trial. J Hepatol 2016; 64: 69-78.
17. Yu JW, Wang GQ, Zhao YH, Sun LJ, Wang SQ, Li SC. The MELD scoring system for predicting prognosis in patients with severe hepatitis after plasma exchange treatment. Hepatobiliary Pancreat Dis Int 2007; 6: 492-496.

18. Nakae H, Yonekawa T, Narita K, Endo S. Are proinflammatory cytokine concentrations reduced by plasma exchange in patients with severe acute hepatic failure? Res Commun Mol Pathol Pharmacol 2001; 109: 65-72

19. Chien MM, Chang MH, Chang KC, et al. Prognostic parameters of pediatric acute liver failure and the role of plasma exchange. Pediatr Neonatol 2019; 60: 389-395.

20. Sogo T, Takahashi A, Inui A, Fujisawa T, Ohira $H$, Takikawa H,Japan AIH Study Group (JAIHSG). Clinical features of pediatric autoimmune hepatitis in Japan: a nationwide survey. Hepatol Res 2018; 48: 286-294.

21. Dumortier J, Scoazec JY, Guillaud O, Hequet $\mathrm{O}$, Hervieu V, Boillot O. Treatment of severe refractory de novo auto-immune hepatitis after liver transplantation with plasmapheresis. Clin Res Hepatol Gastroenterol 2015; 39: e83-e85.

22. Suzuki K, Matsuki Y, Hidaka T, et al. Double filtration plasmapheresis in a patient with autoimmune hepatitis-systemic lupus erythematosus overlap. Intern Med 1993; 32: 725-729. 